\title{
OBESITY AND ITS RELATIONSHIP WITH CANCER: PART II CANCER
}

\author{
Dr. Shashi K. Agarwal \\ Center for Contemporary and Complementary Cardiology \\ 2227 US Highway 1, Suite 309, North Brunswick, NJ 08902, USA \\ E-mail: usacardiologist@gmail.com
}

\begin{abstract}
ABSTARCT
This four-part manuscript briefly reviews the association of obesity with cancer. Part I discussed obesity while this (Part II) will discuss obesity and its impact on cancer. Part III and Part IV will review the association of obesity on fourteen common cancers.
\end{abstract}

\section{Introduction}

Cancer is a dreaded disease and a big barrier to increasing longevity (Capocaccia et al., 2015). It is characterized by uncontrolled cell proliferation that spreads from an initial focal point to other parts of the body, eventually causing death (Steeg, 2016). There were an estimated 19.3 million new cases of cancer diagnosed globally in 2020 (www.iarc.who.int). For both sexes combined, the top 10 cancer types of account for $>60 \%$ of the newly diagnosed cancer cases and $>70 \%$ of the cancer deaths (Howlader et al., 2021). Female breast cancer is the most diagnosed cancer (11.7\% of total cases), closely followed by lung (11.4\%), colorectal (10.0\%), prostate (7.3\%), and stomach (5.6\%) cancers (Sung et al., 2021). In numbers, the World Health Organization (WHO) estimated new cancers in 2020 to be as follows: breast (2.26 million cases); lung (2.21 million cases); colon and rectum (1.93 million cases); prostate (1.41 million cases); skin (nonmelanoma) (1.20 million cases); and stomach (1.09 million cases) (www.who.int). Cancer is prevalent all over the world, Africa reported 1,109,209 while Asia had 9,503,710 new cancer cases in 2020 (https://gco.iarc.fr/today/data/factsheets/populations/935-asia-fact-sheets.pdf). Europe reported 4,398,443, while according to the National Cancer Institute there were 1,806,590 new cases of cancer in the USA in 2020 (Fernandez et al., 2021). Cancer contributed to 233.5 million disability-adjusted life-years in 2017 (Wadasadawala et al, 2021). Cancer is a lethal disease, and over $90 \%$ of cancer mortality is attributed to its metastasis (Steeg, 2016). There were nearly 10 million cancer related deaths in 2020 (Ferlay et al. 2020). The WHO estimates that in 2019, cancer was the first or second leading cause of death before the age of 70 years, in 112 of 183 countries (WHO, 2020). In the world's most populous country, China, cancer is now the leading cause of death (Feng et al., 2019). The most common causes of cancer death in 2020 were: lung (1.80 million deaths); colon and rectum (935 000 deaths); liver (830 000 deaths); stomach (769 000 deaths); and breast (685 000 deaths) (www.who.int). The global 
cancer burden is expected to be 28.4 million cases in 2040, a 47\% rise from 2020 (Sung et al., 2021).

\section{Obesity and Cancer}

Most cancers arise from a complex etiology involving genetic, environmental, and lifestyle factors (Cogliano et al. 2011). Anand et al reported that up to 95\% of cancer events are attributable to lifestyle factors such as physical inactivity, cigarette smoking, poor diet, alcohol, and obesity (Anand et al., 2008). Obesity is an important lifestyle factor and has been linked to an increased risk for several cancers (Bhaskaran et al., 2014; Lauby-Secretan et al., 2016). The United States Cancer Statistics data suggest that overweight and obesity are associated with thirteen different types of cancer, and these cancers made up $40 \%$ of all cancers diagnosed in the United States in 2014 (Steele et al., 2017). Worldwide, the burden of cancer attributable to obesity is $11.9 \%$ in men and $13.1 \%$ in women (Avgerinos et al., 2019). Overweight/obesity was also responsible for $15.1 \%$ of all cancer cases in Scotland and $6.3 \%$ of all cancer cases in England in 2015 (Brown et al., 2015). In Germany, 7\% of the cancers are obesity related (Behrens et al., 2018). According to the American Cancer Society, excess body weight is responsible for about $11 \%$ of cancers in women and about $5 \%$ of cancers in men in the United States (www.cancer.gov).

Obesity is the third leading cause of cancer globally (after smoking and infections) (De Pergola \& Silvestris, 2013). A recently published systematic review found that most cancers were increased by obesity (Gutiérrez-Salmerón et al., 2017). The risk ratio (RR) between obesity and cancer was highest for endometrial cancer (2.54) (Zhang et al., 2014). The RR between obesity and renal cancer was also high (1.77) (Wang \& Xu, 2014). This was followed by pancreatic cancer $(1.48)^{30}$, breast cancer (1.42) (Munsell et al., 2014), liver cancer (1.35) (Rui et al, 2012), colorectal cancer (1.32) (Okabayashi et al., 2012), melanoma (1.31) (García-Jiménez et al., 2016), ovarian cancer (1.30) (Olsen et al., 2007), thyroid cancer (1.29) (Zhao et al.,2012), leukemia (1.26) (García-Jiménez et al., 2016), prostate cancer (1.16) (Hu et al., 2014), gastric cancer (1.13) (Lin et al., 2014), and bladder cancer (1.10) (Qin et al., 2013). Surprisingly, obese people demonstrate a low RR of 0.79 for getting lung cancer (RR for squamous cell carcinoma, adenocarcinoma, and small cell carcinoma of the lung were 0.68, 0.79, and 0.99) (Yang et al., 2013) compared to the non-obese population, indicating an inverse association.

In 2018, 67\% of cancer survivors in the US were overweight or obese (www.usa.gov/federalagencies/national-cancer-institute ). Obese patients with cancer do not thrive well. Several studies have documented treatment-related toxicity in obese children (Amankwah et al., 2016) and obese adults (Calle et al., 2003). Obesity often results in an increase in cancer recurrence, cancer progression, and a negative prognosis in survivors (Schmitz et al., 2013). It also reduces the quality of life in cancer survivors (Rock et al., 2012). Obese survivors of many obesityrelated cancers also have an elevated risk of developing second primary cancers (Sang et al., 2016). Further, more than $40 \%$ of the patients diagnosed with cancer also have comorbid diseases, such as diabetes, chronic obstructive pulmonary disease, heart failure, and coronary artery disease - and obesity is detrimental to these conditions as well (Ogle et al., 2000). Obese cancer patients also experience a high mortality rate (Steele et al., 2017). Among patients with a $\mathrm{BMI} \geq 40 \mathrm{~kg} / \mathrm{m}^{2}$ compared with patients with a normal BMI, mortality from all causes of cancer 
was found to be 52\% higher in men and 62\% higher in women (Pi-Sunyer, 2009). It is estimated that obesity-related cancer deaths in men and women combined account for $6.5 \%$ of all cancer deaths (Islami et al., 2018). Visceral or central obesity is associated with worse cancer outcomes (Allott et al., 2013).

\section{Mechanisms}

Most cancers arise from a complex etiology involving genetic, environmental, and lifestyle factors (Cogliano et al.,2011). Lifestyle factors include obesity (www.health.harvard.edu/). Obesity adversely affects cancer in two ways (Lengyel et al., 2018), (i) promoting carcinogenesis resulting in a higher cancer incidence and (ii) cancer progression resulting in an increased risk of mortality. Obesity contributes to a pro-carcinogenic environment by several biological mechanisms. Obesity induces insulin resistance, hyperinsulinemia, and an abnormally increased blood level of insulin-like growth factor (Gallagher et al., 2015). These changes have been linked to the higher cancer risk seen in diabetics (Gallagher et al., 2015). Other cancers affected include pancreatic, biliary tract, and esophageal cancer in men; breast and endometrial cancer in women; and kidney, liver, and colorectal cancer in both genders (Gallagher et al., 2015). They also exhibit a greater mortality rate (Gallagher et al., 2015). Increased serum IGFs levels are associated with an elevated risk for developing prostate, colorectal, and breast cancer (Wolk et al., 1998; Manousos et al., 1999; Renehan et al., 2004). Androgens and androgenic precursors are converted to estradiol by the enzyme aromatase, the activity of which is increased in obese patients (Morris et al., 2011). This leads to higher levels of estrogens (Crosbie et al., 2010), and an increased breast cancer risk in postmenopausal women (Key et al., 2003). Estrogen also promotes tumorigenesis in endometrial tissue by stimulation of cell proliferation and inhibition of apoptosis (Shaw et al., 2016). This increases the risk of endometrial cancer in obese women by almost 2.6-fold (Shaw et al., 2016). Excessive fat accumulation, such as in visceral obesity, is associated with low levels of adinopectin, which has anti-inflammatory and insulin-sensitizing properties (Cnop et al., 2003). Low adinopectin levels coupled with obesity-induced increased leptin levels (pro-inflammatory) results in an increase in several inflammatory factors such as tumor necrosis factor- $\alpha$ (TNF-a) and interleukin (IL-6) (Boutari et al., 2018). The resultant chronic low-grade inflammation encourages cancer development and progression (Hursting et al., 2010). Obesity is also associated with reactive oxygen species production (Manna et al., 2015), which contributes to tumor promotion via mitochondrial and DNA damage (Włodarczyk \& Nowicka, 2019). Obesity may also have effects on growth factors such as the mammalian target of rapamycin (mTOR) and AMP-activated protein kinase (Sabharwal et al., 2014). Other factors that play a role are obesity enhanced supply of nutrition (Gómez et al., 2019), angiogenesis (Moodi et al., 2021), local inflammation (Stienstra et al., 2012), inhibition of apoptosis/cell death (Cong et al., 2007), and altered intestinal microbiome (Avgerinos et al., 2019). Altered gut microbiome with obesity (Djuric, 2017) and genetic factors may also play a role (Lan et al., 2020). And finally, excess body fat can induce cancer via mechanical effects. Visceral obesity can induce gastroesophageal reflux, which is associated with Barrett's esophagus and esophageal adenocarcinoma (Emerenziani et al., 2013). 


\section{Influence of normal body weight and weight loss on cancer}

A normal body mass index (BMI $<25 \mathrm{~kg} / \mathrm{m} 2$ ) is associated with reduced rates of gastric cardia, gallbladder, pancreatic, ovarian, and thyroid cancers, as well as meningiomas, hepatocellular carcinoma and multiple myeloma (Genkinger et al., 2011; Beral et al., 2012; Arnold et al. 2017). These patients also have a reduced risk of metastasis (Annett et al., 2020). A lower weight gain during adulthood also lowers the risks of colon and kidney cancer, and for postmenopausal women, cancers of the breast, endometrium, and ovaries (Keum et al. 2015).

Intentional weight loss in obese individuals is also beneficial. It specifically reduces the risk of postmenopausal breast and endometrial cancers (Parker \& Folsom, 2003). A systematic review that included 34 studies reported that 16 of the evaluated studies confirmed the benefit of intentional weight loss on cancer (Birks et al., 2012). Weight loss with bariatric surgery also helps reduce cancer incidence and mortality (Christou et al., 2008; Schauer et al., 2019., Castagneto-Gissey et al., 2020). In women, it helps reduce the incidence of cancers such as endometrial, breast, colorectal, non-Hodgkin lymphoma and melanoma (Christou et al., 2008; Schauer et al., 2019, Islam et al., 2020; Castagneto-Gissey et al., 2020). Adams et al. reported that bariatric surgery induced weight loss is associated with a lower cancer risk $(R R=0.55)$ and helps bring their elevated risk of cancer back down to a baseline population risk (Adams et al., 2009). Besides reducing cancer risk, losing weight intentionally has many other health benefits, such as lowering the risk of heart disease and diabetes (Parto \& Lavie, 2017; Schnurr et al., 2020).

Cancer patients often notice an unintentional weight loss. Both radiation and chemotherapy may produce nausea and vomiting (Roila et al., 2010), anorexia (DeWys, 1977), and result in decreased food intake (Postma et al., 2020). Cancer may modify GI motility and digestion, and worsen absorption of nutrients, further enhancing weight loss (Shafi, 2019). Mechanical obstruction by the tumor and psychological factors may also be responsible for poor caloric intake (Diamantis et al., 2011; Ehrsson et al., 2021) A wasting syndrome, cachexia, occurs in many cancers, and especially with pancreatic and gastric cancers (Muliawati et al., 2012). The skeletal muscle wasting in cachexia is associated with significant weight loss (Webster et al., 2020). Unintentional weight loss in cancer patients leads to a reduction in the quality of life and is associated with poor outcomes (Martin et al., 2013). Weight loss, especially due to muscle loss, is associated with poorer tolerance to anticancer therapy (Bachmann et al., 2008), increased risk of postoperative complications (Liu et al., 2020), a reduced quality of life (Naito et al., 2017), and increased mortality (Ryan et al., 2019).

\section{Obesity paradox in cancer}

The obesity paradox has been well described in the cardiovascular and metabolic literature (Aune et al., 2016). Many reports indicate that it also exists in oncology (Petrelli et al., 2020). A recent meta-analysis of 203 observational studies including 6,320,365 participants observed that an obesity paradox exists with lung cancer and melanoma - obesity apparently has a protective effect in these patients (Petrelli et al., 2020). Some researchers attribute this protection to higher levels of skeletal muscle mass in cancer patients with a higher BMI (Cespedes et al., 2018). 
Others claim that this benefit is misleading and is based on several methodological flaws in the studies reporting this phenomenon (Lee \& Giovannucci, 2019).

To summarize, cancer is a deadly disease. It is now the second leading cause of death in the world. Its prevalence is growing rapidly, given the growing and aging population, and the adoption of unhealthy lifestyles. Obesity is a major lifestyle that increases cancer risk. It also promotes cancer progression and hastens death. The mechanistic pathways are several, with heightened inflammation, hyperinsulinemia, and alterations in sex hormone levels. Prevention of weight gain and intentional weight loss is beneficial in stemming these deleterious effects.

Acknowledgment: None

Funding: None

Conflict of interest: None

\section{REFERENCES}

Adams TD, Stroup AM, Gress RE, et al. (2009). Cancer incidence and mortality after gastric bypass surgery. Obesity (Silver Spring) 17:796-802.

Allott E.H., Masko E.M., (2013) Freedland S.J. Obesity and prostate cancer: Weighing the evidence. Eur. Urol. 63:800-809. doi: 10.1016/j.eururo.2012.11.013.

Alsamarrai A, Das SL, Windsor JA, Petrov MS. (2014) Factors that affect risk for pancreatic disease in the general population: a systematic review and meta-analysis of prospective cohort studies. Clin Gastroenterol Hepatol 12: 1635-44. :quiz e103.

Amankwah E, Saenz A, Hale G, Brown P. (2016) Association between body mass index at diagnosis and pediatric leukemia mortality and relapse: a systematic review and metaanalysis. Leukemia Lymphoma 57:1140-8.

Anand P, Kunnumakkara AB, Sundaram C, et al. (2008) Cancer is a preventable disease that requires major lifestyle changes. Pharm Res. (9):2097-116. 10.1007/s11095-008-96619.

Annett S, Moore G, Robson T. (2020) Obesity and Cancer Metastasis: Molecular and Translational Perspectives. Cancers (Basel).12(12):3798. Published 2020 Dec 16. doi:10.3390/cancers12123798.

Arnold M., Renehan A.G., Colditz G.A. (2017) Excess weight as a risk factor common to many cancer sites: Words of caution when interpreting meta-analytic evidence. Cancer Epidemiol. Biomark. Prev. 26:663-665. doi: 10.1158/1055-9965.EPI-16-0940.

Aune D, Sen A, Prasad M, et al. (2016) BMI and all cause mortality: systematic review and non-linear dose-response meta-analysis of 230 cohort studies with 3.74 million deaths among 30.3 million participants. BMJ. 353:i2156.

Avgerinos KI, Spyrou N, Mantzoros CS, Dalamaga M. (2019) Obesity and cancer risk: Emerging biological mechanisms and perspectives. Metabolism. Mar;92:121-135. doi: 10.1016/j.metabol.2018.11.001.

Bachmann J, Heiligensetzer M, Krakowski-Roosen H, et al. (2008) Cachexia worsens prognosis in patients with resectable pancreatic cancer. J Gastrointest Surg. 12(7):1193.

Bhaskaran K., Douglas I., Forbes H., et al. (2014). Body-mass index and risk of 22 specific cancers: a population-based cohort study of 5.24 million UK adults. Lancet, 384, 755765. 
Behrens G., Gredner T., Stock C., et al. (2018). Cancers Due to Excess Weight, Low Physical Activity, and Unhealthy Diet. Dtsch Arztebl Int, 115(35-36). 578-585. https://doi:10.3238/arztebl.2018.0578.

Beral V., Hermon C., Peto R., et al. (2012) Ovarian cancer and body size: Individual participant meta-analysis including 25,157 women with ovarian cancer from 47 epidemiological studies. PLoS Med. doi: 10.1371/journal.pmed.1001200.

Birks S, Peeters A, Backholer K, O'Brien P \& Brown W (2012) A systematic review of the impact of weight loss on cancer incidence and mortality. Obes Rev 13, 868-891.

Boutari C, Mantzoros CS. (2018) Inflammation: A key player linking obesity with malignancies. Metabolism 81:A3-a6.

Brown K.F., Rumgay H., Dunlop C., et al. (2015). The fraction of cancer attributable to modifiable risk factors in England, Wales, Scotland, Northern Ireland, and the United Kingdom in 2015. Br J Cancer, 118(8), 1130-1141. https://doi:10.1038/s41416-0180029-6.

Calle E.E., C. Rodriguez, K. Walker-Thurmond, M.J. Thun. (2003) Overweight, obesity, and mortality from cancer in a prospectively studied cohort of U.S. adults. N Engl J Med, 348, pp. 1625-1638.

Capocaccia R, Gatta G, Dal Maso L. (2015) Life expectancy of colon, breast, and testicular cancer patients: an analysis of US-SEER population-based data. Ann Oncol. 26(6):1263-1268. doi: 10.1093/annonc/mdv131.

Castagneto-Gissey L., Casella-Mariolo J., Casella G., Mingrone G. (2020) Obesity Surgery and Cancer: What Are the Unanswered Questions? Front. Endocrinol. 11:213. doi: 10.3389/fendo.2020.00213.

Cespedes Feliciano EM, Kroenke CH, Caan BJ. (2018) The Obesity Paradox in Cancer: How Important Is Muscle? Annu Rev Nutr. 38:357-379.

Christou NV, Lieberman M, Sampalis F, Sampalis JS. (2008) Bariatric surgery reduces cancer risk in morbidly obese patients. Surg Obes Relat Dis 4:691-5.

Cnop M, Havel PJ, Utzschneider KM, et al. (2003) Relationship of adiponectin to body fat distribution, insulin sensitivity and plasma lipoproteins: evidence for independent roles of age and sex. Diabetologia 46:459-69.

Cogliano VJ, Baan R, Straif K, et al. (2011) Preventable exposures associated with human cancers. Journal of the National Cancer Institute. 103(24):1827-39. doi: 10.1093/jnci/djr483.

Cong L, Gasser J, Zhao J, Yang B, Li F, Zhao AZ. (2007) Human adiponectin inhibits cell growth and induces apoptosis in human endometrial carcinoma cells, HEC-1-A and RL95 2. Endocr Relat Cancer. Sep;14(3):713-20. doi: 10.1677/ERC-07-0065

Crosbie EJ, Zwahlen M, Kitchener HC, Egger M, Renehan AG. (2010) Body mass index, hormone replacement therapy, and endometrial cancer risk: a meta-analysis. Cancer Epidemiol Biomarkers Prev 19:3119-30.

De Pergola G, Silvestris F. (2013) Obesity as a major risk factor for cancer. J Obes. 2013:291546. doi:10.1155/2013/291546

DeWys. W.D. (1977) Anorexia in Cancer Patients.Cancer Res July 1 (37) (7 Part 2) 2354-2358.

Diamantis G, Scarpa M, Bocus P, et al. (2011). Quality of life in patients with esophageal stenting for the palliation of malignant dysphagia. World J Gastroenterol. Jan 14;17(2):144-50. doi: 10.3748/wjg.v17.i2.144. 
Djuric Z. (2017) Obesity-associated cancer risk: the role of intestinal microbiota in the etiology of the host proinflammatory state. Transl Res. 179: 155- 167.

Ehrsson YT, Fransson P, Einarsson S. (2021) Mapping Health-Related Quality of Life, Anxiety, and Depression in Patients with Head and Neck Cancer Diagnosed with Malnutrition Defined by GLIM. Nutrients. Apr 1;13(4):1167. doi: 10.3390/nu13041167.

Emerenziani S, Rescio MP, Guarino MP, Cicala M. (2013) Gastro-esophageal reflux disease and obesity, where is the link? World J Gastroenterol 19:6536-9.

Feng, RM., Zong, YN., Cao, SM. et al. (2019) Current cancer situation in China: good or bad news from the 2018 Global Cancer Statistics?. Cancer Commun 39, 22. https://doi.org/10.1186/s40880-019-0368-6.

Ferlay J, Ervik M, Lam F, et al. (2020) Global Cancer Observatory: Cancer Today. Lyon: International Agency for Research on Cancer; (https://gco.iarc.fr/today, accessed February 2021.

Fernandez CJ, George AS, Subrahmanyan NA, Pappachan JM. (2021) Epidemiological link between obesity, type 2 diabetes mellitus and cancer. World J Methodol. May 20;11(3):23-45. doi: 10.5662/wjm.v11.i3.23.

Islam, K. M. A., Khan, M. A. U., Azhar, S., Ahmed, M. R., Khurram, S., Masood, H., \& Farooq, L. (2020). Comparison Of In Vitro Activity of Colistin with Ceftolozane/Tazobactam against Multi Drug Resistant Pseudomonas Aeruginosa "A Last Line Treatment against Mdr". American International Journal of Multidisciplinary Scientific Research, 6(3), 1-7.

Gallagher EJ, LeRoith D. (2015) Obesity and Diabetes: The Increased Risk of Cancer and Cancer-Related Mortality. Physiol Rev 95:727-48.

García-Jiménez C, Gutiérrez-Salmerón M, Chocarro-Calvo A, et al. (2016) From obesity to diabetes and cancer: epidemiological links and role of therapies. Br J Cancer. 114:716722.

Genkinger J.M., Spiegelman D., Anderson K.E., et al. (2011) A pooled analysis of 14 cohort studies of anthropometric factors and pancreatic cancer risk. Int. J. Cancer. 129:17081717. doi: 10.1002/ijc.25794.

Gómez de Cedrón M, Ramírez de Molina A. (2019) Chapter 28 - Precision nutrition to target lipid metabolism alterations in cancer. In: Faintuch J, Faintuch S. editors. Precision Medicine for Investigators, Practitioners Providers. Academic Press. p. 291-9. 10.1016/B978-0-12-819178-1.00028-9.

Gutiérrez-Salmerón M, Chocarro-Calvo A, García-Martínez JM, de la Vieja A, García-Jiménez C. (2017) Epidemiological bases and molecular mechanisms linking obesity, diabetes, and cancer. Endocrinol Diabetes Nutr. 64:109-117.

Howlader N, Noone AM, Krapcho M, et al. (eds). (2021) SEER Cancer Statistics Review, 1975-2018. National Cancer Institute, posted to the SEER website, April. Accessed April 19, 2021.

https://gco.iarc.fr/today/data/factsheets/populations/935-asia-fact-sheets.pdf - accessed May 30, 2021.

$\mathrm{Hu} \mathrm{MB}, \mathrm{Xu} \mathrm{H}$, Bai PD, Jiang HW, Ding Q. (2014) Obesity has multifaceted impact on biochemical recurrence of prostate cancer: a dose-response meta-analysis of 36,927 patients. Med Oncol. 31:829.

Hursting SD, Berger NA. (2010) Energy balance, host-related factors, and cancer progression. J Clin Oncol. 28:4058-65. 
Islami, F., Goding Sauer, A., Miller, K.D., et al. (2018). Proportion and number of cancer cases and deaths attributable to potentially modifiable risk factors in the United States. CA: A Cancer Journal for Clinicians, 68, 31-54. https://doi:10.3322/caac.21440.

Keum N, Greenwood DC, Lee DH, et al. (2015) Adult weight gain and adiposity-related cancers: a dose-response meta-analysis of prospective observational studies. Journal of the National Cancer Institute 107(2). pii: djv088.

Key TJ, Appleby PN, Reeves GK, et al. (2003) Body mass index, serum sex hormones, and breast cancer risk in postmenopausal women. J Natl Cancer Inst 95:1218-26.

Lan N, Lu Y, Zhang Y, et al. (2020) FTO - A Common Genetic Basis for Obesity and Cancer. Front Genet. Nov 16;11:559138. doi: 10.3389/fgene.2020.559138.

Lauby-Secretan B., Scoccianti C., Loomis D., et al. (2016). Body Fatness and Cancer-Viewpoint of the IARC Working Group. N Engl J Med, 375, 794-8.

Lee DH, Giovannucci EL (2019) The Obesity Paradox in Cancer: Epidemiologic Insights and Perspectives. Curr Nutr Rep. 8:175-181.

Lengyel E., Makowski L., DiGiovanni J., Kolonin M.G. (2018) Cancer as a Matter of Fat: The Crosstalk between Adipose Tissue and Tumors. Trends Cancer. 4:374-384. doi: 10.1016/j.trecan.2018.03.004.

Lin XJ, Wang CP, Liu XD, et al. (2014) Body mass index and risk of gastric cancer: a metaanalysis. Jpn J Clin Oncol. 44:783-791.

Liu X, Xue Z, Yu J, Li Z, Ma Z, Kang W, Ye X, Jiang L. (2020) Risk Factors for Postoperative Infectious Complications in Elderly Patients with Gastric Cancer. Cancer Manag Res. Jun 9;12:4391-4398. doi: 10.2147/CMAR.S253649.

Manna P., Jain S.K. (2015) Obesity, oxidative stress, adipose tissue dysfunction, and the associated health risks: causes and therapeutic strategies. Metab. Syndr. Relat. Disord. 13(10):423-444. doi: 10.1089/met.2015.0095.

Manousos O, Souglakos J, Bosetti C, et al. (1999) IGF-I and IGF-II in relation to colorectal cancer. Int J Cancer 83:15-7.

Martin L, Birdsell L, Macdonald N, et al. (2013) Cancer cachexia in the age of obesity: skeletal muscle depletion is a powerful prognostic factor, independent of body mass index. J Clin Oncol 31 (12): 1539-47.

Moodi M, Tavakoli T, Tahergorabi Z. (2021) Crossroad between Obesity and Gastrointestinal Cancers: A Review of Molecular Mechanisms and Interventions. Int J Prev Med. Feb 24;12:18. doi: 10.4103/ijpvm.IJPVM_266_20.

Morris PG, Hudis CA, Giri D, et al. (2011) Inflammation and increased aromatase expression occur in the breast tissue of obese women with breast cancer. Cancer Prev Res (Phila). Jul;4(7):1021-9. doi: 10.1158/1940-6207.CAPR-11-0110.

Muliawati Y, Haroen H, Rotty LW. (2012) Cancer anorexia - cachexia syndrome. Acta Med Indones. Apr;44(2):154-62

Munsell MF, Sprague BL, Berry DA, Chisholm G, Trentham-Dietz A. (2014) Body mass index and breast cancer risk according to postmenopausal estrogen-progestin use and hormone receptor status. Epidemiol Rev. 36:114-136.

Naito T, Okayama T, Aoyama T, et al. (2017) Unfavourable impact of cancer cachexia on activity of daily living and need for inpatient care in elderly patients with advanced nonsmall-cell lung cancer in Japan: a prospective longitudinal observational study. BMC Cancer. 17(1):800. 
NCI (2020), National Cancer Institute Cancer Trends Progress Report: Life After Cancer. Accessed August 15, 2020.

Ogle, K.S., Swanson, G.M., Woods, N. and Azzouz, F. (2000), Cancer and comorbidity. Cancer, $\quad$ 68: 653-663. https://doi.org/10.1002/(SICI)10970142(20000201)88:3<653::AID-CNCR24>3.0.CO;2-1.

Okabayashi K, Ashrafian H, Hasegawa H, (2012) Body mass index category as a risk factor for colorectal adenomas: a systematic review and meta-analysis. Am J Gastroenterol. 107:1175-85; quiz 1186.

Olsen CM, Green AC, Whiteman DC, et al. (2007) Obesity and the risk of epithelial ovarian cancer: a systematic review and meta-analysis. Eur J Cancer. 43:690-709.

Parker ED, Folsom AR. (2003) Intentional weight loss and incidence of obesity-related cancers: the Iowa Women's Health Study. Int J Obes Relat Metab Disord 27:1447-52.

Parto P, Lavie CJ. (2017)Obesity and CardiovascularDiseases. Curr Probl Cardiol. Nov;42(11):376-394. doi: 10.1016/j.cpcardiol.2017.04.004.

Petrelli F, Cortellini A, Indini A, Tomasello G, Zaniboni A. (2020) Obesity paradox in patients with cancer: A systematic review and meta-analysis of $6,320,365$ patients. medRxiv 04.28. 20082800.

Pi-Sunyer X. (2009) The medical risks of obesity. Postgrad Med. 121:21-33.

Postma EM, Kok DE, de Graaf C, Kampman E, Boesveldt S. (2020) Chemosensory perception and food preferences in colorectal cancer patients undergoing adjuvant chemotherapy. Clin Nutr ESPEN. Dec;40:242-251. doi: 10.1016/j.clnesp.2020.09.012

Qin Q, Xu X, Wang X, Zheng XY. (2013) Obesity and risk of bladder cancer: a meta-analysis of cohort studies. Asian Pac J Cancer Prev. 14:3117-3121.

Renehan AG, Zwahlen M, Minder C, O'Dwyer ST, Shalet SM, Egger M. (2004) Insulin-like growth factor (IGF)-I, IGF binding protein-3, and cancer risk: systematic review and meta-regression analysis. Lancet 363:1346-53.

Rock CL, Doyle C, Demark-Wahnefried W, et al. (2012) Nutrition and physical activity guidelines for cancer survivors. CA Cancer J Clin. 62:243-274.

Roila F., Herrstedt J., Aapro M., et al. (2010) Guideline update for MASCC and ESMO in the prevention of chemotherapy and radiotherapy-induced nausea and vomiting: results of the Perugia consensus conference. Annals of Oncology. 21(5):v232-v243. doi: 10.1093/annonc/mdq194.

Rui R, Lou J, Zou L, et al. (2012) Excess body mass index and risk of liver cancer: a nonlinear dose-response meta-analysis of prospective studies. PLoS One. 7:e44522.

Ryan AM, Prado CM, Sullivan ES, Power DG, Daly LE. (2019) Effects of weight loss and sarcopenia on response to chemotherapy, quality of life, and survival. Nutrition. NovDec;67-68:110539. doi: 10.1016/j.nut.2019.06.020.

Sabharwal SS, Schumacker PT. (2014) Mitochondrial ROS in cancer: initiators, amplifiers or an Achilles' heel? Nat Rev Cancer 14:709-21.

Sang Min Park, Young Ho Yun, Young Ae Kim, et al. (2016). Prediagnosis Body Mass Index and Risk of Secondary Primary Cancer in Male Cancer Survivors: A Large Cohort Study. Journal of Clinical Oncology, 34, 4116-4124.

Schauer D.P., Feigelson H.S., Koebnick C., et al. (2019) Bariatric Surgery and the Risk of Cancer in a Large Multisite Cohort. Ann. Surg. 269:95-101. doi: 10.1097/SLA.0000000000002525. 
Schmitz KH, Neuhouser ML, Agurs-Collins T, et al. (2013) Impact of obesity on cancer survivorship and the potential relevance of race and ethnicity. Journal of the National Cancer Institute 105(18):1344-1354.

Schnurr T.M., Jakupović H., Carrasquilla G.D., et al. (2020) Obesity, unfavourable lifestyle and genetic risk of type 2 diabetes: A case-cohort study. Diabetology. 63:1324-1332. doi: 10.1007/s00125-020-05140-5.

Shafi MA. (2019) Gastrointestinal Motility Issues in Cancer Patients. Curr Gastroenterol Rep. Dec 10;21(12):69. doi: 10.1007/s11894-019-0738-x.

Shaw E, Farris M, McNeil J, Friedenreich C. (2016) Obesity and Endometrial Cancer. Recent Results Cancer Res 208:107-36.

Steeg P.S.. (2016) Targeting metastasis. Nat. Rev. Cancer, 16 (4), p. 201.

Steele C.B., Thomas C.C., Henley S.J., et al. (2017) Vital signs: Trends in incidence of cancers associated with overweight and obesity-United States, 2005-2014. MMWR Morb. Mortal. Wkly. Rep. 66:1052-1058. doi: 10.15585/mmwr.mm6639e1.

Stienstra R, Tack CJ, Kanneganti TD, Joosten LA, Netea MG. (2012) The inflammasome puts obesity in the danger zone. Cell Metab 15:10-8.

Sung H, Ferlay J, Siegel RL, Laversanne M, Soerjomataram I, Jemal A, Bray F. (2021) Global Cancer Statistics 2020: GLOBOCAN Estimates of Incidence and Mortality Worldwide for 36 Cancers in 185 Countries. CA Cancer J Clin. May;71(3):209-249. doi: $10.3322 /$ caac. 21660.

Wadasadawala T, Sen S, Watekar R, et al. (2021) Economic Distress of Breast Cancer Patients Seeking Treatment at a Tertiary Cancer Center in Mumbai during COVID-19 Pandemic: A Cohort Study. Asian Pac J Cancer Prev. 22(3):793-800. Published 2021 Mar 1. doi:10.31557/APJCP.2021.22.3.793.

Wang F, Xu Y. (2104) Body mass index and risk of renal cell cancer: a dose-response metaanalysis of published cohort studies. Int J Cancer. 135:1673-1686.

Webster JM, Kempen LJAP, Hardy RS, Langen RCJ. (2020) Inflammation and Skeletal Muscle Wasting During Cachexia. Front Physiol. Nov 19;11:597675. doi: 10.3389/fphys.2020.597675.

Włodarczyk M., Nowicka G. (2019) Obesity, DNA damage, and development of obesity-related diseases. Int. J. Mol. Sci. 20(5):E1146. doi: 10.3390/ijms20051146

Wolk A, Mantzoros CS, Andersson SO, et al. (1998) Insulin-like growth factor 1 and prostate cancer risk: a population-based, case-control study. J Natl Cancer Inst 90:911- 5.

WHO (2020). World Health Organization. Global Health Estimates 2020: Deaths by Cause, Age, Sex, by Country and by Region, 2000-2019. Accessed December 11, 2020. who.int/data/gho/data/themes/mortality-and-global-health-estimates/ghe-leading-causesof-death.

www. cancer.gov.

www.health.harvard.edu.

www.iarc.who.int.

https://www.usa.gov/federal-agencies/national-cancer-institute.

www.who.int

Yang Y, Dong J, Sun K, et al. (2013) Obesity and incidence of lung cancer: a meta-analysis. Int J Cancer. 132:1162-1169. 
Zhang Y, Liu H, Yang S, Zhang J, Qian L, Chen X. (2014). Overweight, obesity and endometrial cancer risk: results from a systematic review and meta-analysis. Int $\mathrm{J}$ Biol Markers. 29:e21-e29.

Zhao ZG, Guo XG, Ba CX, (2012). Overweight, obesity and thyroid cancer risk: a metaanalysis of cohort studies. J Int Med Res. 2012;40:2041-2050.

\section{Copyrights}

Copyright for this article is retained by the author(s), with first publication rights granted to the journal. This is an open-access article distributed under the terms and conditions of the Creative Commons Attribution license (http://creativecommons.org/licenses/by/4.0/). 